occurs with androgen therapy) did occur in the three youngest children studied by Tanner and Whitehouse. Antibodies to human growth hormone have been found in the scia of some patients receiving it, and they have sometimes been associated with a poor response to treatment. ${ }^{12}$

The treatment of patients with other types of dwarfism has usually not been so rewarding as the treatment of dwarfism due to hypopituitarism. Children in whom no specific cause for their short stature can be established have been termed "primordial" or "idiopathic" dwarfs, and probably the causes of their condition vary. Acceleration of growth in some of these patients by growth hormone has been reported, ${ }^{13}$ while in others the results have been disappointing. ${ }^{11}$ The existence of a state of isolated deficiency of growth hormone in the absence of deficiency of other anterior pit. itary hormones has been recorded, ${ }^{14}$ and Tanner and Whitehouse diagnosed this condition in 16 of their patients, 10 of whom responded well to treatment. The response of patients with gonadal dysgenesis to treatment has been poor, ${ }^{11} 13$ though some acceleration of growth in two patients has been reported. ${ }^{15}$ Many workers hoped that therapy with growth hormone might provide a treatment for the dwarfism which is such a prominent feature of long-term treatment of children with corticosteroids, ${ }^{16}$ as these substances antagonize the action of growth hormone peripherally, ${ }^{17}$ as well as suppressing its release from the pituitary. ${ }^{18}$ Studying two such children, Tanner and Whitehouse found no response to growth-hormone therapy in one, and a slight acceleration of growth in the other.

In assessing children with dwarfism for possible treatment with growth hormone accurate diagnosis is essential. This has been greatly aided by the measurement of the levels of growth hormone in the serum, usually during an insulintolerance test, as hypoglycaemia has been shown to be a potent stimulus for the release of growth hormone. ${ }^{19}$ Measuremest of the metabolic response to a short course of growth hormone has been found ${ }^{12}$ to be a useful guide in predicting response to long-term therapy, though other workers have not found it helpful. ${ }^{20}$ As growth hormone is extracted from human pituitary glands, its supply is necessarily restricted. In Britain the Medical Research Council has arranged for the collection of pituitary glands with the co-operation of pathologists throughout the country. Nevertheless, there are still many patients who might be expected to benefit from treatment with growth hormone for whom there is no material available. It is therefore to be hoped that as many pathologists as possible will help in collecting the glands, and particulars of the collection procedure may be obtained from the M.R.C.

\section{Resuscitation and the Nurse}

The report in the Supplement (p. 15) of the latest meeting of the Joint Committee of the British Medical Association and the Royal College of Nursing illustrates the rapidly evolving role of the nurse in the changing medical scene. Within the memory of senior members of the profession student nurses were not expected to take the blood pressure or give intramuscular injections. Now they must understand intermittent positive-pressure respirators and cardiac monitors, apparently give intravenous injections, and even undertake the onerous responsibility of initiating treatment of cardiac arrest.

The young nurse asks herself three questions about resuscitation: Will I be equal to the task when I first have to perform it? On what patients should resuscitation be attempted ? Will the result be happy or distressing ? The first can be answered by providing effective first-aid equipment, prompt medical support, and above all by detailed and really practical teaching. It is useless to suggest that a patient in a hospital bed should be placed on the floor if a nurse unaided is incapable of getting a heavy patient there without injuring him.

The question of whom to resuscitate is the most difficult of the three. Nobody dies nowadays, said a group of student nurses ; they have cardiac arrest, and sometimes it is permanent. At opposite extremes the decision is easy. Sudden collapse of unknown cause and cardiac arrest during an acute illness or operation require energetic treatment. On the other hand, the close of a long life or an incurable illness should be allowed to occur peacefully. Between these two are many patients about whom a decision may be hard to reach, or fraught with emotion. If the nurse is left to make it for herself she may try resuscitation where no good result can be expected, and if on the other hand she is told not to perform it she may feel, however illogically, that this is equivalent to euthanasia.

As to the results of resuscitation, what most nurses fear is not that the attempt may be unavailing but that the patient may live with faculties grossly impaired. Because each nurses's personal experience of treating cardiac arrest is small, the numerical chances of complete-success are also small. Doctors in charge of resuscitation units who see many cases are rewarded by some successful results. They must see that nurses are told about them and so encouraged to be alert and prompt to begin resuscitation.

\section{Treatment of Haemophilia}

There are between 1,500 and 2,000 males with haemophilia in Great Britain. They lack a globulin factor in their plasma that is necessary for the normal coagulation of blood. The haemostatic mechanism is restored to normal by infusion of the missing factor, antihaemophilic globulin (A.H.G.), but the effect of the infusion is of short duration. Half the activity disappears from the plasma in 8 to 12 hours, and thus the management of all but the most minor haemorrhages requires the daily infusion of sufficient material to maintain a concentration of A.H.G. of at least 20 to $30 \%$ of the level found in normal people.

Not only does infused A.H.G. disappear rapidly from the recipient's blood but the A.H.G. in freshly drawn normal blood falls equally rapidly. Thus the preparation of material suitable for treating attacks of bleeding in haemophiliacs has presented formidable problems. Even the delay between bleeding a donor and finally freezing the plasma results in loss of almost half the A.H.G., and many preparations may lose most of their potency by the time they are required for use. In practice it often proved difficult to infuse a sufficiently large volume of fresh plasma to obtain fully effective levels of A.H.G. in bleeding haemophiliacs, and though concentrates of human material have been prepared they have been scarce.

The management of haemophilia has been transformed by the observations of J. G. Pool and J. Robinson ${ }^{1}$ that A.H.G. in plasma comes out of solution, together with fibrinogen and other proteins, at low temperatures and can be separated from the rest of the plasma in this state. In practice fresh plasma 
is rapidly frozen and allowed to thaw at 4 or $8^{\circ} \mathrm{C}$. The protein remaining out of solution at this temperature, the cryoprecipitate, which contains the bulk of A.H.G., is separated. Thus most of the A.H.G. in $250 \mathrm{ml}$. of plasma is left in a small volume, and the A.H.G. from a litre of plasma can be given to a haemophiliac in a few minutes as a single injection with a $20-\mathrm{ml}$. syringe. Anyone who can recall the battlefield atmosphere of a hospital ward containing a severely bleeding haemophiliac, with blood donors lining the corridors, will appreciate how the management of these patients has been transformed. The benefits of these methods of treatment are apparent from the papers in the B.M.F. this week by Dr. D. L. Brown and his colleagues (page 79) and Dr. Enid Bennett and her colleagues (page 88).

The practical implications of treatment with A.H.G. in this way are considerable. Patients must be persuaded to present themselves as soon as bleeding starts and not attempt to sit it out in the hope that it will prove to be relatively minor. Relief of pain, restoration of mobility to a joint, and cessation of further bleeding can be expected within a few hours of prompt administration of cryoprecipitate. The treatment may have to be repeated during the next two or three days. This can be done entirely on an outpatient basis, so that the saving in the use of hospital beds should prove considerable. More continuous and adequate schooling for haemophiliac children should now become possible.

The implications for blood-transfusion centres are also considerable. Many thousands of units of blood have to be processed to supply enough cryoprecipitate, and the blood has to be processed within a few hours of collection. The transfusion services have responded to this challenge, and at present production is probably adequate to meet the requirements for minor attacks of bleeding, but has not yet reached the stage where stocks are sufficient to cover all emergencies. In March two haemophiliacs were admitted to hospitals in the London area with major gastrointestinal haemorrhage only to find that the bulk of A.H.G. was committed to the treatment of a third patient with haemophilia who had been in a motorcar accident. One of the patients had to be transferred to a hospital out of the London area where supplies of A.H.G. were available and the second was treated through the generous supply of material by other hospitals and transfusion centres.

The cost of expanding production of A.H.G. to meet this type of situation is not likely to be large. The largest expense is for the double plastic bags used initially to collect the blood and thereafter to separate the cryoprecipitate. Once the cryoprecipitate has been taken off, the red cells and plasma are united, and this blood can and should be used in the normal way. Reduction in the use of hospital beds by haemophiliacs which the widespread use of cryoprecipitate should bring about may well offset any additional costs in producing the material. It it also desirable that some of the cryoprecipitate should be tested for activity, either by the transfusion centres or by special units equipped to perform reliable assays. Though this procedure will not guarantee that any particular dose of this labile material has adequate activity, it may help to keep up the standard of activity in general. At present considerable effort is devoted to assaying plasma levels of A.H.G. after infusion. These tests are of great value in determining the correct dosage and frequency of administration, but they might suitably be given up as a

1 Pool, J. G., and Robinson, J, Brit. F. Haemat., 1959, 5, 24. routine when some form of quality control is available in checking the A.H.G. content of cryoprecipitate. It is helpful if haemophiliac patients, where possible, attend centres with an interest in coagulation disorders and where supplies of cryoprecipitate are maintained. But the ease with which it can be given should enable patients who do not live within easy reach of such a centre to obtain treatment through their local hospitals.

\section{Drinking Drivers}

The Road Safety Bill has now completed its progress through Parliament, and is expected to come into effect in the autumn of this year. Last month the Home Office sent a circular to all chief constables and police authorities drawing their attention to the likelihood of " a considerable increase in the number of cases" of drivers suspected of offences connected with drinking, and strongly advising the appointment of designated doctors and deputies in all areas.

The Road Traffic Act of 1.962 covers driving under the influence of drugs as well as alcohol, and it remains on the Statute Book for use on occasions when the new legislation is unsuitable. In the past doctors called out by the police to examine drivers suspected of offences were faced with conducting a difficult examination, to be followed by a clinical decision that was often borderline, and finally a timeconsuming court appearance that could be embarrassing and worrying, particularly if the doctor had had little previous experience of the courts. Under the new legislation a driver will commit the offence of driving or being in charge of a vehicle under the influence of drink if the concentration of alcohol in his blood, " as ascertained from a laboratory test for which he subsequently provides a specimen under section 3 of this Act, exceeds the prescribed limit at the time he provides the specimen." 1 The doctor's duty will be limited to taking the sample of blood and, as heretofore, in giving an opinion on the fitness or otherwise of the accused to be detained. Doctors have always recognized the importance of excluding injury or illness in driving cases, particularly if the suspect has been involved in an accident. The Bill provides that evidence that a specimen of blood was taken can be given by certificate, subject to the right of the defence to require the attendance of the doctor at the court.

If the police authorities follow the advice of the Home Office, and enough doctors agree to serve, it should soon be unusual for any doctor other than a designated police surgeon to be asked to see a driver charged with an offence under the new legislation. The police surgeons themselves will probably see more drivers, but they should make fewer court appearances, and the arguments in court on the interpretation of levels of blood alcohel should become a thing of the past.

This modernization of the law on drinking and driving is in line with the recommendations made by the B.M.A. ${ }^{2-4}$ over the last 12 years, but it has one danger. A level of 80 $\mathrm{mg} . / 100 \mathrm{ml}$. of alcohol in the blood is one which few ordinary social drinkers could achieve without nausea, and one which may not be attained before 9 to 12 single whiskies have been drunk-though it could be attained with a much smaller quantity taken on an empty stomach. It is certainly not the upper

\footnotetext{
Road Safety Bill (179), 1967. H.M.S.O.

2 Recognition of Intoxication, 1954. B.M.A.

- Relation of Alcohol to Road Accidents, 1960. B.M.A.

- The Drinking Driver, 1965. B.M.A.
} 